\title{
CES
}

COOPERATIVISMO E ECONOMÍA SOCIAL

Núm. 40 (2017-2018), páxs. 281-293

ISSN: $1130-2682$

\section{ALGUMAS LINHAS DE FRONTEIRA ENTRE O CONTRATO A FAVOR DE TERCEIRO E OS PACTOS SUCESSÓRIOS NO QUADRO DAS ASSOCIAÇÕES MUTUALISTAS. ANOTAÇÃO AO ACÓRDÃO DO STJ, DE 10.01.2017, PROC. N. ${ }^{\circ}$ 2303/12.2YXLSB-B.L1.S1, 6. ${ }^{a}$ SECÇÃO}

SOME BOUNDARY LINES BETWEEN CONTRACTS IN FAVOR OF THIRD PARTY AND CONTRACTUAL INHERITANCE LAW WITHIN THE FRAMEWORK OF INVESTMENTS MANAGED BY FINANTIAL INSTITUTIONS WITH A SCOPE OF SOCIAL SOLIDARITY. A COMMENTARY ON THE DECISION OF THE PORTUGUESE SUPREME COURT OF JANUARY 10, 2017, CASE NO. 23023/12.2YXLSB-B.L1.S1, 6 SECTION

\author{
Jỗo Paulo F. Remédio Marques ${ }^{1}$
}

1 Prof. Dr. Iuris. Professor da Faculdade de Direito da Universidade de Coimbra (Portugal). Pátio da Universidade, 3004-528, Coimbra. Correio electrónico: remedio@fd.uc.pt. 



\section{Introdução. A Sucessão Contratual e A Admissibilidade dos Pactos Sucessórios}

tento o envelhecimento populacional, a escassez de fontes de remune-
ração do aforro dos particulares e a rigidez da disciplina jurídica da su-
cessão legitimária, compreende-se que o caso objeto do presente comentário jurisprudencial respeite a um problema cada vez mais central do direito dos contratos, qual seja o da delimitação de duas áreas problemático-judicativas:

(a) a área do livre exercício de poderes de autodeterminação da vontade que se contém na área dos contratos inter vivos (maxime, gratuitos); face à

(b) área de atuação das pessoas marcada por normas imperativas, deveres. sujeições e proibições legais resultantes do fenómeno da sucessão mortis causa de situações jurídicas ativas e passivas, aqui onde a liberdade e autonomia contratuais cedem perante o interesse da proteção da «pequena família» constituída pelos herdeiros legitimários.

O caso apreciado e julgado pelo STJ português — pese embora a justeza e a bondade da solução que nele foi tirada - situa-se numa zona de indeterminação legal respeitante à validade de determinados contratos, para alguns considerados como pactos sucessórios inválidos, em particular doações por morte nulas ao abrigo do artigo $946 .^{\circ} \mathrm{CC}$, ex vi do art. 2028. ${ }^{\circ}$ do mesmo Código. Indeterminação, esta, que prejudicar os (verdadeiramente ${ }^{1}$ ) interessados na celebração deste tipo de pactos e as pessoas coletivas (no caso uma associação mutualista) que neles podem intervir na qualidade de partes.

Atualmente, os ordenamentos jurídicos tendem a convergir no alargamento da autonomia privada, em particular da autonomia do autor da herança plasmada no reforço da liberdade de testar; todavia, constata-se uma enorme diversidade de regimes entre os diversos ordenamentos jurídicos no que respeita à questão da (in) validade sucessão contratual ${ }^{2}$ e da qualificação de alguns negócios jurídicos de

\footnotetext{
1 Ou seja, os sujeitos que não utilizam tais pactos com fins simulatórios ou para defraudar ilegitimamente os herdeiros legitimários, os credores do falecido ou a autoridade tributária e aduaneira.

2 Por exemplo, na Espanha, os arts. 658 e 1271, 2, do Código Civil proíbem genericamente os pactos sucessórios, pese embora alguns ordenamentos das Regiões os admitiam limitadamente em favor dos cônjuges ou descendentes (Catalunha e Galiza) ou em geral (Navarra e País Basco). Na França, embora há muito sejam proibidos (arts. 722 e 1130 do Code Civil), admite-se a «cláusula comercial» a favor do cônjuge supérstite (desde 1965), contida em convenção antenupcial, bem como a renúncia antecipada e por acordo, em caso de divórcio, à sucessão do cônjuge (desde 1975), a celebração de pactos sobre sucessões futuras pelos herdeiros (1978), tendo em mira a continuidade das sociedades comerciais (à exceção das sociedades anónimas), a instituição de doações de bens futuros em convenção antenupcial ou na constância do casamento; por fim, a Lei n ${ }^{\circ}$ 2006-728, de 23/07/2006, previu o alargamento das hipóteses em que é permitida a liberalité-partage, para além dos casos em que já eram feitas pelos
} 
atribuição de vantagens patrimoniais a terceiros como sendo inter vivos ou mortis causa.

Na resolução deste tipo de litígios, é sempre decisivo saber se e a morte é $a$ causa do negócio jurídico (celebrado em vida com o disponente, no caso com uma associação mutualista) ou se, pelo contrário, é somente este facto natural gerador do efeito (ou um dos efeitos, uma espécie de termo suspensivo) do concreto negócio jurídico. E isto independentemente de a causa do negócio ser uma causa donandi ou outra (v.gr., causa solvendi).

Esta questão é cada vez mais pertinente à luz das múltiplas alternativas de fazer frutificar o aforro privado (para além dos contratos de depósito celebrados com instituições bancárias ${ }^{3}$, temos, designadamente, v.gr., fundos de investimento no quadro da private equity, seguros de vida capitalização tomados junto de

ascendentes a favor dos descendentes. Na Bélgica, autoriza-se (desde 2003) a renúncia antecipada dos cônjuges aos respectivos direitos sucessórios, em convenção antenupcial ou em convenção celebrada na constância do casamento que altere o regime de bens, se existirem filhos de algum deles antes do casamento ou seus descendentes (nova redação do art. 1308 do Code Civil). No Luxemburgo somente é admitida a donation-partage e a instituição contratual feita pelos nubentes ou pelos cônjuges. Na Holanda permitem-se as doações mortis causa, não obstante sejam proibidos genericamente os pactos sucessórios (art. 4:42, 4:4, a, alínea $a$ ), do Código Civil). Na Alemanha, o $B G B$ admite a celebração de pactos sucessórios designativos e doações mortis causa (§ 2274 ss.). Na Áustria, são somente admitidos os pactos sucessórios entre os cônjuges e em seu favor, contanto que não disponha de mais de três quartos do património do seu património (§ 1249 ss., do respetivo Código Civil). Na Argentina, o novo Código Civil e Comercial autoriza o pacto de família relativo à exploração de empresas e participações societárias de qualquer tipo, podendo nele incluir-se estipulações respeitantes a direitos hereditários futuros e compensações em favor de outros legitimários, contanto que não afetem a legítima subjetiva, os direitos do cônjuge e de terceiros (art. 1010, n. 2). Na Turquia, os pactos sucessórios são geralmente admitidos (art. 485. ${ }^{\circ}$ ss. do Código Civil deste país). Na Grécia, os pactos sucessórios são proibidos, mas admitem-se as doações mortis causa, desde que revogáveis e alguns tipos de partilha em vida. No Brasil, o artigo $426 .^{\circ}$ do Código Civil determina, genericamente, que "não pode ser objecto de contrato a herança de pessoa viva", ainda que alguma doutrina admita a partilha antecipada dos bens do de cuius realizada inter vivos e essa mesma doutrina consinta que os nubentes possam dispor reciprocamente, em convenção antenupcial, da respetiva sucessão futura. Sobre isto, cfr. N. Ascensão E Silva, "Em torno das relações entre o direito da família e o direito das sucessões - o caso particular dos pactos sucessórios no direito internacional privado", Textos de Direito da Família para Francisco Pereira Coelho, Coimbra, Imprensa da Universidade, 2016, p. 429 ss., pp. 449-453, nota 32 ss.; Daniel de Bettencourt Silva Morais, A Autodeterminação Sucessória por Testamento ou por Contrato?, Cascais, Principia, 2016, 2017, pp. 163-308; Andrea Fusaro, «L'espansione dell'autonomia privata in ambito successorio nei recenti interventi legislativi francesi ed italiani», comunicação apresentada no XVIII Colloquio biennale AIDC Patrimonio, persone e nuove tecniche di governo del diritto - Incentivi, premi, sanzioni alternative, que teve lugar Ferrara, entre 10 e 12 Maio de 2007, acessível no seguinte endereço eletrónico: www.crdc.unige.it/docs/articles/RelazioneFerrara.pdf; J. P. Remédio MarqueS, «Em torno do planeamento sucessório: o Código Civil português e as formas alternativas de sucessão mortis causa», Boletim da Faculdade de Direito, vol. 94, 2018, tomo I, n. ${ }^{\circ} 8$.

3 Atenta a baixíssima remuneração, no seio da zona euro, destes depósitos junto de instituições bancárias, em virtude da atual política monetária do Banco Central Europeu e das contraprestações contratadas e exigíveis pelas instituições bancárias para abrir a conta e efetuar a sua manutenção. 
seguradoras, capitais pagáveis em prazos determinados ou por morte do tomador ou associado, no caso das associações mutualistas, etc.) e dele fazer beneficiar quem bem aprouver ao aforrador (designadamente terceiros, os herdeiros não legitimários ou alguns destes em detrimento dos outros).

O nódulo do caso sub iudice era assim o de saber se atribuição efetuada pela associação mutualista (scilicet, o capital que esta é obrigada a pagar aos beneficiários; no caso aos descendentes do associado) opera fora (extrinsecamente) do mecanismo da sucessão hereditária, não se regendo pelos princípios desta ou se, ao invés, as disponibilidades monetárias capitalizadas pela associação mutualista devem ser consideradas bens da herança do associado subscritor, as quais transitam mortis causa para o património dos seus herdeiros aceitantes.

\section{A FACTUAlidade SUBJACENTE E A ENVOLVENTE JURÍDiCO- CONTRATUAL}

A falecida/Inventariada efetuou em vida a uma associação mutualista (Montepio Geral) a entrega a esta última de determinadas disponibilidades monetárias, no quadro do benefício denominado «Capitais de Reforma ou Complemento de Rendimento», ficando investida no direito de, ou bem que receber desta associação mutualista certo rendimento mínimo anual, ou bem que ser reembolsada das entregas feitas e seu acúmulo de rendimento, ou, ainda, obter a conversão do capital acumulado numa pensão. Tratou-se de uma aplicação financeira posta à disposição dos associados pelo Montepio Geral, então denominada «Capitais de Reforma/Complemento de Rendimento». Porém, ficou estipulado que, para o caso de morte da associada subscritora, por meio de incorporação dos termos legais previstos no Regulamento de Benefícios do Montepio Geral, o capital acumulado era para ser entregue a certas pessoas, in casu às filhas da Inventariada. O litígio surgiu porque uma das três filhas (a cabeça de casal) pretendeu relacionar como bem da herança da associada o capital acumulado à data do óbito desta associada na sequência da subscrição da aplicação financeira (isto para que a herança da falecida mãe pudesse pagar certas dívidas a uma instituição de solidariedade social de que ela, filha, era a sócia gerente), enquanto as outras filhas se opuseram a tal entendimento e operação, defendendo que esse capital acumulado resultante da frutificação da disponibilidades monetárias originariamente transferidas para a gestão do Montepio Geral lhes pertencia por direito próprio, não tendo sido objeto de transmissão hereditária.

De acordo com o art. $1 .^{\circ}$, n. $^{\circ} 1$, do Regulamento de Benefícios do Montepio Geral, esta aplicação financeira «consiste na entrega de determinadas quotas que serão geridas e capitalizadas pelo Montepio Geral e transformadas numa pensão, quando o subscritor o desejar». $\mathrm{O}$ n. ${ }^{\circ} 2$ do mesmo artigo estabelece que «o subscritor tem a possibilidade de, a qualquer momento, se fazer reembolsar, total ou 
parcialmente, nas condições estabelecidas no presente Regulamento, do capital acumulado». Last but not the least, o art. $7 .^{\circ}$ do mesmo Regulamento estipulava que $« \mathrm{O}$ subscritor deve designar os seus beneficiários e a forma de distribuição do capital acumulado, em caso de morte» e que «Em caso de morte do subscritor, o capital acumulado até à data em que aquele se verificou será integralmente entregue aos beneficiários designados, aplicando-se, na falta destes, o disposto no artigo $20^{\circ}$ das Disposições Gerais deste Regulamento» — os itálicos são meus. Além disso, os associados ao subscreverem quaisquer modalidades de benefícios devem pagar uma quota, cujo montante é definido nos termos regulamentares (arts. $31^{\circ}$ e $32 .^{\circ}$ do citado Regulamento).

\section{ANÁlise E DISCUSSÃo DO CASO}

Tal como como o depósito bancário (que é um depósito irregular, pois tem por objeto coisas fungíveis - art. $1205^{\circ}$ do CC), as disponibilidades monetárias entregues ao Montepio Geral tornam-se propriedade desta instituição mutualista pelo facto da mera entrega (negócio real quoad effectum). O depositário fica obrigado a restituir outro tanto do mesmo género e qualidade ao depositante com o capital acumulado na decorrência da gestão financeira feita a tais disponibilidades monetárias, se for caso. O Montepio Geral é a entidade que, ao abrigo de um fim previdenciário ou de segurança social, gere e capitaliza essas disponibilidades monetárias. Daqui resulta que nada impede, no direito português, a celebração de um contrato de seguro de capitalização (tal como um de depósito bancário) provido de uma cláusula a favor de terceiro a cumprir no momento da morte do promissário. Estaremos, como o STJ bem salientou, perante um contrato a favor de terceiro mortis causa que, para além do testamento e do contrato sucessório, é admitido entre nós (art. $451 .^{\circ}$, n. $^{\circ} 1, \mathrm{CC}$ ).

É evidente que, curando-se de um mero depósito bancário (o que não é o caso sub iudicio, cujo enquadramento legal, ao abrigo do DL n. ${ }^{\text {o }} 72 / 90$, é claro ${ }^{4}$ ) o pretenso donatário está sempre salvo de demonstrar o animus donandi - pois este é facto constitutivo do direito de haver para si o equivalente monetário das quantias entregues à instituição — , bem como os herdeiros do outro depositante

\footnotetext{
4 Vale dizer, estas associações mutualistas realizam a concessão de benefícios de segurança social e de saúde destinados a reparar as consequências da verificação de factos contingentes relativos à vida e à saúde dos associados e seus familiares e a prevenir, na medida do possível, a verificação desses factos (art. 2. ${ }^{\circ}$ do citado DL), bem como para a concretização dos seus fins de segurança social, as associações mutualistas podem prosseguir, designadamente, a modalidade de «Capitais pagáveis por morte ou no termo de prazos determinados» (art. 3. ${ }^{\circ}$ do mesmo diploma), podendo os associados subscrever quaisquer das modalidades de benefícios previstas no dito Regulamento de Benefícios. De resto, as prestações pecuniárias devidas pelas associações mutualistas aos associados e a outros beneficiários (v.gr., pessoas não qualificadas como herdeiras legitimárias) não podem ser cedidas a terceiros nem penhoradas e prescrevem a favor das mesmas associações (art. 36. ${ }^{\circ}$, idem).
} 
podem sempre demonstrar que tais disponibilidades monetárias movimentadas a débito logo após a sua morte deste integram a sua massa da herança e devem, por isso, ser relacionadas e partilhadas entre os herdeiros do depositante. Isto porque a abertura de contas bancárias pode ser um negócio-meio de outros negócios jurídicos, tais como a doação, o mandato (com e sem representação) e o penhor ${ }^{5}$. De igual sorte, o depositante sobrevivo está também livre de demonstrar que tais quantias, embora depositadas em regime contitularidade, lhe pertencem por inteiro ${ }^{6}$. Isto é assim quanto aos depósitos bancários.

O caso aqui em anotação, decidido pelo STJ, assume contornos completamente diferentes. Na verdade, o STJ subsumiu (e bem) esta aplicação financeira ao contrato a favor de terceiro a cumprir depois da morte do promissário na modalidade de seguro de vida/capitalização. Isto porque o subscritor poderia designar (como, aliás, designou) os beneficiários e a forma de distribuição do capital acumulado, em caso de morte; nesta hipótese de morte do subscritor, o capital acumulado até à data em que a morte se verificou seria, nos termos do citado Regulamento de Benefícios, integralmente entregue pelo Montepio Geral aos beneficiários designados.

Com efeito, no contrato ao favor de terceiro mortis causa o direito é adquirido pelo terceiro independentemente de aceitação, embora o momento da aquisição seja diferido no tempo. O beneficiário recebe o valor do seguro/capitalização; porém, não o recebe do de cuius, mas, sim, diretamente da entidade mutualista/ seguradora ${ }^{7}$. Donde não são aplicáveis as normas dos arts. $2050 .^{\circ}$ e $2249 .^{\circ}$ do CC

5 C. Ferreira De Almeida, Contratos, III, Contratos de Liberalidade, de Cooperação e de Risco, 2. ${ }^{\text {a ed., }}$ Coimbra, Almedina, 2013, p. 38, referindo-se ao mandato e ao penhor enquanto relações subjacentes possíveis.

6 J. P. Remédio Marques, A Penhora e a Reforma do Processo Civil - Em Especial a Penhora de Depósitos Bancários e do Estabelecimento, Lisboa, Lex, 2000, pp. 87-88, quanto à penhora do saldo das contas plurais e do conteúdo e repartição do ónus da prova dos depositantes.

7 Assim, já, J. de Oliveira Ascensão, Direito Civil, Direito das Sucessões, 4. . ed., Coimbra, Coimbra Editora, 1989, p. 54, salientando que «há certas formas de aquisição por morte que nada têm a ver com a sucessão. Processam-se longe desta, obedecendo a princípios próprios», referindo-se, inter alia, aos seguros de vida estabelecidos pelo de cuius; J. C. Moitinho De Almeida, Coimbra, Coimbra Editora, 2009, pp. 362-363; J. Duarte Pinheiro, O Direito das Sucessões Contemporâneo, 2. ${ }^{a}$ ed., Associação Académica da Faculdade de Direito de Lisboa, Lisboa, 2027, p. 151, segundo o qual, a propósito do contrato a favor de terceiro sob a modalidade de seguro de vida, observa que «o capital seguro não é um bem integrante da herança do promissário (...) o capital encontra-se, ou encontrava-se, no património da empresa seguradora, que o entrega na sequência de um contrato a título oneroso celebrado com o falecido promissário. Só o prémio de seguro, contribuição do promissário efectuada em vida deste, é que se pode considerar ficticiamente integrado numa herança alargada, não confinada ao relictum», ou seja, somente tais prémiso podem ser qualificados como doações indirectas submetidas à restituição à massa da herança para efeitos de cálculo da legítima subjetiva dos herdeiros legitimários e sujeitos à colação, à imputação de liberalidades e à redução por inoficiosidade; no mesmo sentido, R. Lobo Xavier, Planeamento Sucessório e Transmissão do Património à Margem do Direito das Sucessões, Porto, Universidade Católica Editora, 2016, pp. 114-115, segundo a qual «o contrato a favor de terceiro 
português, relativamente à aceitação da herança ou do legado. O direito do terceiro beneficiário nunca integra o património do promissário (art. $4500^{\circ}$ do mesmo Código). E daí não é transmissível segundo as regras da sucessão mortis causa. Donde, não deve esse capital ser relacionado como bem da herança pelo cabeça de casal. O terceiro, por razões de ordem prática (ou, melhor, por meio de uma fictio iuris $^{8}$ ), adquire originariamente o direito (teoria da aquisição originária). Para este promissário (a aqui de cuius), a prestação ao terceiro (às filhas) traduz um ato unilateral de disposição, já que a promessa é revogável enquanto o promissário estiver vivo (art. 448. ${ }^{\circ} \mathrm{CC}$ ), já que o terceiro apenas adquire o direito apos a morte daquele (art. $451 .^{\circ}$, n. 1, CC). Daqui resulta que o promissário ou as partes podem revogar o benefício antes da morte desse promissário. O terceiro deve sobreviver ao promissário, pelo que benefício não se transmite aos seus herdeiros.

É verdade que, no direito estrangeiro" ${ }^{9}$, as opiniões não são unânimes em considerar o contrato a favor de terceiro como atribuição inter vivos, pois há quem (doutrina que é, apesar de tudo, minoritária ${ }^{10}$ ) defenda que o contrato de seguro de vida a favor de terceiro post mortem está muito próximo do subsistema do Direito das Sucessões, sendo uma forma de sucessão privilegiada ${ }^{11}$ — ainda que o concreto benefício a favor do terceiro fosse excluído por não pertencer à herança (do promissário) ${ }^{12} \mathrm{e}$, outros, quem, de forma mais radical, sustente que devem ser aplicadas ao caso as regras respeitantes à instituição de herdeiros ${ }^{13}$ ou as regras relativas aos legados ou, no mais, que se está perante uma atribuição mortis causa indireta (doação indireta) se e quando fosse realizada cumprindo a forma

com efeitos à morte do promitente constitui um ato inter vivos e não viola a proibição dos pactos sucessórios», pois «a morte do promissário náo é assim causa de atribuição a favor do terceiro, constitui o termo a partir do qual a aquisição do direito ocorrida no momento da conclusão do contrato produz os seus efeitos».

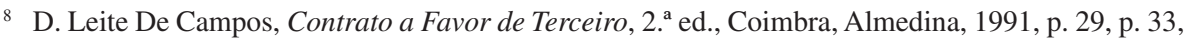
pp. 35-36.

9 Cfr., para mais desenvolvimentos desta análise comparativa, Daniel de B. Silva Morais, Autodeterminação Sucessória por Testamento ou por contrato?, Cascais, Princípia, 2016, p. 814 ss., Daniel de B. Silva MoraIs, Revolução sucessória - Os Institutos Alternativos ao Testamento no Século XXI, Cascais, Principia, 2018, pp. 68-75.

${ }^{10}$ Sobre os critérios de cuja verificação depende a existência de pacto sucessório ilícito, cfr. Maria francesca Cocuccio, Divieto dei Patti Successori e Patto di Famiglia, Milano, Giuffrè, 2016, p. 28.

${ }^{11}$ Andrea Zoppini, «Contributo allo studio delle disposizione testamentarie 'in forma indiretta'», Studi in onore di Pietro Rescigno, II, Diritto Privato (1. Persone, famiglia, successioni e proprietà), Milano, Giuffrè, 1998, p. 919 ss.

${ }^{12}$ Andrea Zoppini, «Contributo allo studio delle disposizione testamentarie 'in forma indiretta'», cit., p. pp. 933-934.

${ }^{13}$ Manfred Harder, «Das Valutaverhältnis beim Vertraga zugunsten Dritter auf den Todesfall», Zeitschrift für das gesamte Familienrecht, 1976, p. 418 ss., p. 428; Karl-Heinz Hoffmann, «Der Vertrag zugunsten Dritter von Todes wegen - Eine Erbeinsetzung in Valutaverhältnis», Archiv für die civilistische Praxis, vol. 158, 1959-1960, p. 178 ss., pp. 196-197. 
dos testamentos ${ }^{14}$. Por exemplo, na doutrina espanhola alguns (embora minoritariamente) veem o contrato a favor de terceiro a cumprir depois da morte do promissário (como é o caso do seguro de vida) uma doação mortis causa no que respeita à relação de valuta, aqui onde o terceiro beneficiário adquire os montantes correspondentes ao capital seguro de forma derivada; capital, este que deve ser contabilizado para efeitos de cálculo da legítima ${ }^{15}$. Outros (posição maioritária) consideram-no um negócio inter vivos, pois a atribuição do direito é alcançada com a relação de cobertura, a qual ocorre é em vida do promissário; esta atribuição apenas estará condicionada à morte à morte do promissário e à sobrevivência do beneficiário ${ }^{16}$.

No caso concreto, os terceiros/beneficiários eram curiosamente herdeiros legitimários do promissário. Em caso de pré-morte do beneficiário, os seus herdeiros são chamados à titularidade da posição jurídica decorrente da promessa (art. $451 .^{\circ}$, n. $^{\circ}$ 2, CC), havendo como que uma espécie de representação sucessória: os herdeiros do terceiro adquirem por direito próprio e não por via sucessória. $\mathrm{E}$ antes da morte do promissário a situação do terceiro é idêntica à do nomeado em testamento, cabendo-lhe uma simples expetativa fáctica. E, ainda - na linha do decidido pelo STJ - , como referi, o capital do seguro ou acumulado (gerido pelo Montepio Geral) não entra na massa da herança do promissário por morte deste. O que deve ser relacionado é, isso sim, o montante dos prémios (no caso de contrato de seguro) ou as quantias (quotas e demais despesas) pagas pelo promissário (ora de cuius) à entidade mutualista para realizar a referida subscrição, as quais geraram a vantagem que o Montepio Geral deverá entregar diretamente aos beneficiários. Deste modo, o ato de disposição mortis causa a favor de terceiro (talqualmente um seguro de vida ou de capitalização), em que a prestação deve ser realizada após a morte do promissário, é determinado pela vontade unilateral do disponente. Vale dizer, o terceiro adquire a posição de credor sem haver a necessidade de entre ele e o promissário estipulante existir acordo quanto a esse ato de disposição. O que aproxima sobremaneira este ato às disposições testamentárias, pois estamos perante uma forma de disposição indireta mortis causa onde a atribuição realizada em benefício do terceiro decorre diretamente do próprio contrato.

Todavia, o contrato a favor de terceiro afasta-se do figurino do testamento e do contrato sucessório, uma vez que o primeiro é tripolar. O terceiro nada adquire do património do promissário. O direito nasce ex novo no património do tercei-

${ }^{14}$ Giorgio Giampiccolo, Il contenuto atípico del testamento. Contributo ad una teoria dell'atto di ultima voluntà, Milano, Giuffrè, 1954, p. 306 ss.

${ }^{15} \mathrm{M}^{\mathrm{a}}$ del Pino Acosta Mérida, Seguro de vida y derecho de succesiones, Madrid, Dykinson, 2005, pp. 70-71.

${ }^{16}$ Klaus Jöchen Albiez Dohrman, Negocios atributivos «post mortem», Barcelona, Cedecs Editorial, 1998, pp. 173-174. 
ro (beneficiado), o que traduz uma dimensão social (ou previdencial) do direito adquirido pelo beneficiário, assim se compreendendo que as associações mutualistas estejam, ao abrigo da lei portuguesa, autorizadas a celebrar estes contratos com os seus associados. Não se viola, desta maneira, a proibição da celebração de pactos sucessórios, uma vez que o art. $9466^{\circ}$, n..$^{\circ} 1$, do $\mathrm{CC}$ admite exceções à ilicitude de tais pactos, as quais podem ser estabelecidas em lei especial fora do CC português. O nascerem tais prestações ex novo explica por que motivo o que o promissário pagou à instituição financeira é que se submete a algumas regras do direito das sucessões, designadamente, a redução por inoficiosidade e a colação, se o benefício for efetuado em favor de herdeiro legitimário. O remanescente gerido e frutificado por esta, não se submete a tais regras. Há como que uma doação indireta no seguro de vida a favor de terceiro: o objeto da doação indireta são os prémios por parte do estipulante. Por isso, estes (e só estes) devem ser conferidos e eventualmente sujeitos à obrigação de colação se os beneficiários forem descendentes. Já o capital seguro, pago pela associação mutualista (in casu, o Montepio Geral) após a morte do tomador a um terceiro beneficiário, designado em testamento, não integra o acervo hereditário do tomador e como tal não está sujeito a redução por inoficiosidade ${ }^{17}$. Redutíveis por ofensa à legítima são, também por isso, as quantias prestadas pelo tomador do seguro à seguradora, no âmbito desse seguro (veja-se o Decreto-Lei n. ${ }^{\circ} 72 / 2008$, de 16 de abril) ou as quantias correspondentes às quotas que, no caso sub iudice, o tomador subscreveu por ocasião da celebração deste seguro de capitalização. Na verdade, o valor dos prémios pagos (e só este) está eventualmente sujeito a um conjunto de obrigações e vicissitudes do direito das sucessões, quais sejam a colação, a redução por inoficiosidade, a imputação e a impugnação pauliana. Todavia, creio que a totalidade do benefício atribuído ao terceiro deve achar-se sujeito ao regime da revogação por ingratidão do donatário e das proibições de doar ${ }^{18}$. A morte do estipulante promissário (no caso sub iudice, o associado da instituição mutualista) pode ser encarada como um termo de que dependem os efeitos do negócio ou uma condição, em função dos resultados interpretação dessas declarações de vontade. $\mathrm{O}$ direito é adquirido pelo terceiro beneficiário independentemente da sua aceitação, não sendo aplicáveis os arts. $2050 .^{\circ}$ e $2249 .^{\circ}$ do CC.

No caso sub iudice, somente está sujeito às regras do fenómeno hereditário a quantia correspondente à soma das quotas entregues pelo de cuius ao Montepio Geral, a fim de constituir o capital cuja gestão o associado lhe entrega; já o eventual rendimento (gerado precipuamente pela gestão efetuada pelo Montepio Ge$\mathrm{ral}$ ) que lhes seja atribuído, deduzido de eventuais reembolsos, deve ser excluído da massa dos bens da herança.

\footnotetext{
17 Não está, destarte, sujeito ao ataque dos credores do falecido, nem dos herdeiros legitimários deste.

${ }^{18}$ Daniel de B. Silva Morais, Autodeterminação Sucessória, Cascais, Principia, 2017, p. 879.
} 
$\mathrm{O}$ art. $946 .^{\circ}$, n. $^{\circ} 1, \mathrm{CC}$ exceciona certos casos da proibição das doações mortis causa. Ora, o contrato a favor de terceiro constitui precisamente uma exceção à proibição das doações mortis causa. No contrato a favor de terceiro - e interessa aqui aquele contrato a favor de terceiro (seja o que é subscrito com uma instituição seguradora ou bancária, seja o que é celebrado com uma instituição mutualista) a cumprir depois da morte do promissário — há, na verdade, o intuito de beneficiar um terceiro por conta do promissário, adquirindo este um direito por força de um contrato em que não foi parte (artigo $443 .^{\circ}$, n. $^{\circ} 1, \mathrm{CC}$ ). Atenta a natureza sucessória deste tipo de contrato, ele é revogável pelo promissário até à sua morte ${ }^{19}$, o que o equipara, neste caso, ao negócio testamentário.

O promissário goza de poderes de disposição por morte diferentes e mais alargados do que aqueles que pode exercitar por meio do negócio testamentário ou do contrato sucessório, pois tais poderes incidem sobre bens de que não é titular. Daqui resulta que o contrato a favor de terceiro cujo cumprimento deva ocorrer após a morte do promissário traduz uma forma autónoma de disposição mortis causa atuante à margem das regras do Direito das Sucessões. Isto porque, por exemplo, no contrato de seguro de vida/seguro de capitalização ou no seguro ligado a fundos de investimento, o beneficiário não adquire as quantias a título sucessório, embora corresponda, por via de regra (como o STJ insinou neste aresto) a uma atribuição patrimonial a título gratuito, à qual deverá ser aplicado o regime das liberalidades ${ }^{20}$.

De igual sorte, tal como resulta da decisão do STJ que agora comento, a jurisprudência dos tribunais superiores tem decidido maioritariamente que somente são atingidas pela inoficiosidade as quantias entregues pelo tomador do seguro ao segurador e que o capital seguro pago pela companhia seguradora, após a morte do tomador, ao terceiro beneficiário designado em testamento não integra o acervo hereditário do testador, não estando assim sujeito à redução por inoficiosidade ${ }^{21}$.

\footnotetext{
${ }^{19}$ Daniel de B. Silva Morais, Autodeterminação Sucessória, 2017, p. 877.

${ }^{20}$ Não sendo assim convocável o regime das indignidades sucessórias, do direito de acrescer, pois o beneficiário não adquire o direito a título sucessório - neste sentido, R. Lobo Xavier, Planeamento Sucessório, Universidade Católica Portuguesa, 2016, p. 141; R. Capelo De Sousa, Lições de Direito das Sucessões, I, 4. ${ }^{\mathrm{a}}$ ed, Coimbra, Coimbra Editora, 2000, pp. 34-35.
}

${ }^{21}$ Acórdão da Relação de Coimbra, 5/03/2013 (VIrGílio Mateus), proc. n. ${ }^{\circ}$ 930/11.4T2AVR.C1, in www.dgsi.pt; acórdão do STJ, de 17/06/2014 (FerNANDES Do VALE), proc. n. ${ }^{\circ}$ 930/11.4T2AVR.C1.S1, loc. cit., nos termos do qual o valor da prestação a que a segurador se encontra vinculada a pagar ao beneficiário «não se encontra abarcado pelas disposições relativas à colação, à imputação, redução de liberalidades e impugnação pauliana, cuja aplicabilidade, no caso, se mostra limitada às quantias prestadas pelo tomador do seguro ao segurador»; idem, de 12/11/2013 (GREGóRIo DA SILVA Jesus), proc. . $^{\circ}$ 530/10.6TJPRT.P1.S1, loc. cit., nos termos do qual mesmo os seguros de vida ligados a fundos de investimento, cobrindo o risco de vida e de morte da pessoa segura pode constituir «estruturalmente um verdadeiro contrato a favor de terceiro definido pelo art. $443 .^{\circ}$ do $\mathrm{CC}$, e estando a aquisição do direito à prestação do seguro, pelo terceiro beneficiário, dependente da morte do segurado, não integra o património deste o capital segurado»; acórdão da Relação do Porto, de 20/06/2017 (MARIA De Jesus 
Ora, independentemente da natureza jurídica da entidade emitente e gestora da aplicação financeira (no caso, uma associação mutualista), parece que as razões subjacentes a este regime devem ser aplicadas a todas as situações análogas.

E esta solução que aponta para a validade de uma atribuição mortis causa por meio da realização de um contrato a favor de terceiro também explica - em Portugal, contrariamente ao que ocorre noutros ordenamentos jurídicos - a admissibilidade do depósito irregular (de coisas fungíveis: art. 1205 . $^{\circ} \mathrm{CC}$ ) na modalidade de um depósito bancário com uma cláusula a favor de terceiro a cumprir no momento da morte do promissário ${ }^{22}$, nos termos do artigo $451 .^{\circ}$, n. $^{\circ} 1$, do mesmo Código e das regras específicas do depósito irregular, designadamente, o artigo

PEREIRA), proc. n. ${ }^{\circ}$ 1144/13.4TJPRT-A.P, loc. cit., segundo o qual «Não é de relacionar no inventário o capital segurado que se destinava não ao de cujus contratante mas a terceiros beneficiários (um deles a cabeça-de-casal) sem prejuízo de se relacionarem as quantias que o inventariado despendeu com os respectivos prémios»; acórdão da Relação de Coimbra, de 5/03/2013 (VIrGílıIo Mateus), proc. n. ${ }^{\circ}$ 930/11.4T2AVR.C1, loc., cit., o qual decidiu que «Celebrado um seguro de vida em caso de morte do seu tomador, o capital seguro, pago pela seguradora após a morte do tomador a um terceiro beneficiário, designado em testamento por aquele tomador do seguro, não integra o acervo hereditário deste e como tal não está sujeito a redução por inoficiosidade», acrescentando que «O que é redutível por ofensa da legítima são as quantias prestadas pelo tomador do seguro ao segurador no âmbito desse seguro, por força do regime jurídico aprovado pelo DL nº 72/2008 de 16.4»; idem, de 14/12/2005 (HÉLDER RoQuE), proc. n. ${ }^{\circ}$ 3669/05; acórdão da Relação do Porto, de 21/02/2018 (FERNANDo SAMõES), proc. n. ${ }^{\circ}$ 2717/12.8TBPVZ.P1, segundo o qual «Os seguros ligados a fundos de investimento são instrumentos de captação de aforro estruturado e assumem a natureza jurídica de contratos de seguros de vida (...) Estruturalmente, são contratos a favor de terceiro e estando a aquisição do direito à prestação do seguro, pelo terceiro beneficiário, dependente da morte do segurado, não integra o património deste o capital objecto do seguro» e que «Havendo beneficiários designados na respectiva apólice e sobrevivendo eles à pessoa segura, os herdeiros desta não podem obter a prestação do capital seguro, pelo que não podem exigir a sua entrega à herança do segurado»; acórdão da Relação do Porto, de (JUDITE PIRES), proc. n. ${ }^{\circ}$ 530/10.6TJPRT.P1, loc. cit., nos termos do qual «Falecendo o autor da herança sem deixar herdeiros legitimários, não carece de ser relacionada no respectivo inventário a quantia recebida da seguradora por terceiro beneficiário por ele indicado, aquando da celebração do contrato de seguro de capitalização, para receber a correspondente indemnização em caso de morte do segurado antes do termo do contrato»; acórdão da Relação de Guimarães, de 5/01/2017 (JoÃo Peres COELHO), proc. n. ${ }^{\circ} 1192 / 14.7 T B V C T-A . G 1$, de harmonia com o qual «Nos seguros de vida associados a empréstimos bancários o terceiro a favor de quem é feita a promessa adquire directamente o direito à prestação, pelo que esta não integra, nem transita pela herança do promissário (...) Por isso, falecendo o autor da herança sem deixar herdeiros legitimários, não carece de ser relacionada no inventário aberto por óbito do mesmo a quantia recebida da seguradora por terceira beneficiária, por ele indicada aquando da celebração de um seguro de vida grupo contributivo do tipo capitalização»; tb., entre outros, P. Romano Martinez/A. Costa Oliveira/L. Cunha Torres/M. ${ }^{a}$ Eduarda Ribeiro/J. Pereira Morgado/José Vasques, Lei

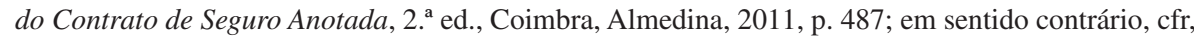
o acórdão da Relação de Lisboa, de 14/04/2005 (FÁtıMa GaLANTE), proc. n. ${ }^{\circ}$ 1851/2005-6, acessível em www.dgsi.pt; idem, de 13/05/2004 (GiL RoQUe), proc. n ${ }^{\circ} 3329 / 2004-6$, loc. cit.

${ }^{22}$ Tb., neste sentido, Daniel de B. Silva Morais, Autodeterminação Sucessória, 2017, p. 908. Esta estipulação exibe vantagens relativamente ao seguro de vida, pois aquele não está sujeito à aleatoriedade do contrato e à circunstância de o tomador do seguro pagar os prémios à companhia de seguros; de igual sorte o negócio testamentário também não garante a rápida satisfação da restituição das quantias 
$1144 .^{\circ}$ deste Código, que estatui que as coisas mutuadas se tornam propriedade do mutuário e que este fica obrigado a restituir outro tanto do mesmo género e qualidade (artigo 1142. ${ }^{\circ}$, idem) ${ }^{23}$.

\section{Conclusão}

A distinção entre atos negociais mortis causa e inter vivos - saber quando ocorre sucessão mortis causa com a convocação das regras do Direito das Sucessões - nem sempre é fácil. A proibição da celebração de pactos sucessórios e a cominação da nulidade à quase totalidade de tais pactos é, infelizmente, uma constante nos ordenamentos jurídicos latinos. A questão tem sido apreciada e julgada nos Tribunais Portugueses a respeito de seguros vida/capitalização emitidos por companhias de seguro e instituições bancárias. A decisão do STJ que agora comentei posiciona a questão numa dimensão jurídica jurídico-problemática análoga: a emissão destes seguros de capitalização por parte de entidades mutualistas (in casu, o Montepio Geral) de disponibilidades monetárias entregues por um seu associado. Por via da utilização da figura do contrato a favor de terceiro a doutrina portuguesa e a maioria da jurisprudência dos Tribunais Superiores tem vindo - acertadamente no meu juízo - a entender que as quantias traduzidas nas aplicações financeiras de capitalização, subscritas junto destas instituições, no caso sub iudice, pela inventariada junto do Montepio Geral em favor dos beneficiários (id est, o capital acumulado à data do óbito) não devem ser relacionadas, pois não integram os bens hereditários (a sua quantificação e faculdade de exigibilidade não existe), constituindo direitos de crédito próprios dos beneficiários. Tais montantes (ou a faculdade da sua exigibilidade) não existem à data da morte do tomador; só com o seu óbito é que nasce o direito de serem pagos (a quem o tomador tiver indicado). Não ocorre assim um fenómeno de transmissão por morte, nem uma ofensa à regra da proibição da generalidade dos pactos sucessórios prevista no art. $946 .^{\circ}$, n. $^{\circ} 1$, do CC português. O que deve ser relacionado e objeto de partilha hereditária é apenas a quantia que a associada entregou ao Montepio Geral a título das subscrições que realizou, à semelhança dos prémios pagos pelo tomador do seguro no contrato de seguro. E somente essa quantia estará, se for caso, disso sujeita ao mecanismo da imputação, à obrigação de colação e à redução por inoficiosidade.

ao beneficiário, nem o secretismo associado aos deveres de observância do sigilo bancário entre as instituições financeiras e os respectivos clientes.

${ }^{23}$ Poderia, de iure condendo, limitar-se o montante de que o beneficiário poderá dispor, em atenção à proteção de eventuais legitimários e à evasão fiscal. 